\title{
EFEKTIVITAS PENERAPAN MODEL DISCOVERY LEARNING TERHADAP HASIL BELAJAR IPA
}

\section{THE EFFECTIVENESS OF DISCOVERY LEARNING MODEL APPLICATION TOWARDS THE SCIENCE LEARNING OUTCOMES}

\author{
Masayu Diska Prilliza*, Nur Lestari, I Wayan Merta, dan I Putu Artayasa \\ Program Studi Pendidikan Biologi, Fakultas FKIP Universitas Mataram, Mataram, Indonesia \\ *Email: heediska@gmail.com
}

Diterima: 11 Desember 2019. Disetujui: 18 Desember 2019. Dipublikasikan: 2 Maret 2020

\begin{abstract}
Abstrak: Penelitian ini bertujuan untuk mengetahui efektivitas penerapan model discovery learning terhadap hasil belajar IPA peserta didik di kelas VII SMP Negeri 14 Mataram semester genap tahun ajaran 2018/2019. Jenis penelitian ini adalah kuantitatif bersifat eksperimen semu (quasi experimental) dengan desain yaitu Nonequivalent Control Group Design. Populasi dalam penelitian ini yakni seluruh kelas VII di SMP Negeri 14 Mataram yang terdiri dari 8 kelas dan berjumlah 255 orang. Penentuan sampel penelitian menggunakan teknik cluster sampling sehingga terpilihlah 2 kelas. Penentuan kelas eksperimen dan kelas kontrol menggunakan undian sehingga terpilih kelas VII B sebagai kelas kontrol dan kelas VII A sebagai kelas eksperimen. Instrumen yang digunakan dalam penelitian adalah tes hasil belajar ranah kognitif dan dianalisis menggunakan analisis kovarian (ANAKOVA). Nilai signifikansi pada nilai posttest terkoreksi nilai pretest adalah $0,000<0,05$. Hal ini menunjukkan bahwa nilai pretest peserta didik dan model pembelajaran yang digunakan dapat mempengaruhi nilai posttest yang diperoleh peserta didik. Berdasarkan NGain-score yang diperoleh, nilai rata-rata pada kelas eksperimen yaitu 0,4747. Sedangkan nilai rata-rata pada kelas kontrol yaitu 0,3747 . Terdapat peningkatan hasil belajar yang lebih baik pada kelas eksperimen yang menggunakan model pembelajaran discovery learning dibandingkan dengan kelas yang menggunakan metode konvensional. Kesimpulan hasil penelitian menunjukkan bahwa penerapan model discovery learning efektif terhadap hasil belajar IPA peserta didik di kelas VII SMP Negeri 14 Mataram semester genap tahun ajaran 2018/2019.
\end{abstract}

Kata Kunci: Discovery Learning, Hasil Belajar

Abstract: The purpose of this study was to determine the effectiveness of discovery learning model application towards the science learning outcomes of students in VII grade of SMP Negeri 14 Mataram even semester of 2018/2019 academic year. The type of this study was quasi-experimental with the design was Nonequivalent Control Group Design. The populations in this study were all classes in VII grade of SMP Negeri 14 Mataram which consisted of 8 classes and the number of students was 255 people. The determination sample of this study was using cluster sampling techniques so that 2 classes were chosen. The determination of the experimental class and control class used a lottery so that class VII B was chosen as a control class and class VII A as an experimental class. The instrument that used in this study was a cognitive learning outcomes test and the test was analyzed using analysis of covariance (ANAKOVA). The significance value in the posttest which was corrected by pretest value was $0,000<0.05$. The data showed that the pretest scores of students and the learning model which was used can influence the obtained posttest scores of students. Based on the NGain score, the average of experimental class was 0.4747. Meanwhile, the average of the control class was 0.3747 . There was an enhancement in learning outcomes that were better in the experimental class which was using the discovery learning model compared to the class that was using the conventional method. The conclusion of this study shows that the application of discovery learning model is effective on the science learning outcomes of students in VII grade of SMP Negeri 14 Mataram even semester 2018/2019 academic year.

Keywords: Discovery Learning, Learning Outcomes

\section{PENDAHULUAN}

Pendidikan merupakan salah satu usaha yang digunakan untuk memperbaiki kualitas sumber daya manusia. Pendidikan adalah usaha sadar dan terencana untuk mewujudkan suasana belajar dan proses pembelajaran agar peserta didik secara aktif mengembangkan potensi dirinya untuk memiliki kekuatan spiritual keagamaaan, pengendalian diri, kepribadian, kecerdasan, akhlak mulia, serta keterampilan yang diperlukan dirinya, masyarakat, bangsa, dan negara [1]. Salah satu cara untuk memperoleh pendidikan adalah dengan mengikuti kegiatan pembelajaran di sekolah.

Kegiatan pembelajaran di sekolah saat ini tidak lagi berpusat pada guru melainkan pada peserta didik. Selain itu, pembelajaran yang awalnya hanya 
dilakukan dengan cara ceramah sudah tergantikan dengan diterapkannya pendekatan ilmiah. Pendekatan ilmiah (scientific approach) merupakan suatu pendekatan pembelajaran yang menekankan pada aktifitas peserta didik dalam mengamati, menanya, menalar, mencoba, dan membuat jejaring dalam mengikuti kegiatan pembelajaran di sekolah [2].

Kegiatan pembelajaran di sekolah pada umumnya dilakukan di dalam kelas antara guru dengan peserta didik. Di SMP Negeri 14 Mataram, kegiatan pembelajaran IPA untuk kelas VII berlangsung di dalam kelas dan pada materi tertentu saja dilakukan di luar kelas. Berdasarkan hasil observasi dan wawancara terhadap guru mata pelajaran IPA kelas VII di SMP Negeri 14 Mataram, terdapat beberapa permasalahan-permasalahan yang muncul ketika proses pembelajaran IPA berlangsung di kelas. Permasalahan-permasalahan tersebut antara lain: 1) terdapat peserta didik yang memiliki motivasi belajar yang rendah; 2) sebagian peserta didik tidak fokus pada saat pembelajaran berlangsung; 3) sebagian peserta didik kurang aktif selama kegiatan pembelajaran. Timbulnya permasalahanpermasalahan tersebut dapat berdampak pada hasil belajar peserta didik. Dapat diketahui dari hasil wawancara dengan guru mata pelajaran IPA kelas VII bahwa tidak semua peserta didik dapat mencapai nilai KKM ketika diberikan soal ulangan.

Hasil analisis nilai ulangan peserta didik pada semester ganjil tahun ajaran 2018/2019 dengan menggunakan salah satu materi IPA menunjukkan bahwa persentase peserta didik yang mendapatkan nilai $<75$ adalah $52,55 \%$ pada kelas VII di SMP Negeri 14 Mataram. Permasalahan-permasalahan di atas menjadi dasar penelitian. Permasalahanpermasalahan yang muncul selama proses pembelajaran diduga dapat berpengaruh terhadap hasil belajar IPA peserta didik di kelas VII SMP Negeri 14 Mataram.

Pembelajaran matematika dengan menggunakan model pembelajaran discovery learning pada materi perbandingan ditinjau dari kemampuan matematika siswa di kelas VII-A SMP Negeri 2 Ngadiluwih adalah efektif [3]. Selanjutnya pembelajaran discovery lebih efektif dalam meningkatkan hasil belajar siswa kelas $\mathrm{X}$ pada kompetensi dasar analisis rangkaian kemagnetan di SMK 1 Pundong [4]. Kemudian adanya pengaruh hasil belajar (posttest) dengan model pembelajaran guided discovery learning dapat disimpulkan pula bahwa selain berpengaruh model pembelajaran guided discovery learning juga efektif untuk dilakukan pada proses pembelajaran khususnya pada materi geometri [5]. Model discovery learning memiliki pengaruh terhadap efektivitas pembelajaran [6]. Pembelajaran IPA dengan model discovery learning lebih efektif dibandingkan dengan model ekspositori terhadap hasil belajar siswa dalam kategori sedang. Hasil belajar siswa yang menerapkan model discovery learning memiliki perbedaan dengan pembelajaran yang menerapkan model ekspositori [7]. Ada perbedaan rata-rata pada kelas V MI Tsamrotul Huda Kecapi Jepara tahun ajaran 2015/2016 antara pembelajaran yang menggunakan model discovery learning dengan pembelajaran yang menggunakan metode konvensional. Oleh karena itu, hasil belajar siswa dalam mata pelajaran IPA materi pesawat sederhana dengan menggunakan model discovery learning lebih efektif dibandingkan dengan pembelajaran dengan menggunakan metode konvensional [8].

Upaya yang dapat dilakukan dalam mengatasi permasalahan-permasalahan yang telah diuraikan di atas adalah dengan menerapkan suatu model pembelajaran yang menuntut peserta didik agar aktif dalam mengikuti kegiatan pembelajaran sehingga dapat memberikan pengaruh yang baik dalam hasil belajar. Salah satu model pembelajaran tersebut adalah model discovery learning. Selain karena didukung dengan materi pembelajaran yang membahas pencemaran lingkungan, juga masih kurangnya penelitian yang ditemukan dengan menggunakan model discovery learning pada materi pencemaran lingkungan. Sehingga dilakukanlah penelitian dengan menggunakan model discovery learning pada materi IPA pencemaran lingkungan.

Model discovery learning terdiri dari beberapa tahapan. Dalam proses pembelajaran, penerapan model discovery learning dapat menuntun peserta didik agar lebih aktif. Penerapan model discovery learning terhadap hasil belajar IPA peserta didik dapat menjadi bahan acuan untuk dilihat efektivitas model discovery learning terhadap hasil belajar IPA peserta didik dalam suatu materi IPA.

\section{METODE PENELITIAN}

Jenis penelitian ini adalah penelitian kuantitatif bersifat eksperimen semu (quasi experimental). Penelitian dilaksanakan di kelas VII SMP Negeri 14 Mataram semester genap tahun ajaran 2018/2019. Variabel bebas dalam penelitian ini adalah penerapan model discovery learning. Sedangkan variabel terikat dalam penelitian ini adalah hasil belajar IPA peserta didik.

Populasi dalam penelitian ini adalah seluruh peserta didik di kelas VII SMP Negeri 14 Mataram yang berjumlah 255 orang yang terdiri dari 8 kelas (VII A-VII H). Teknik pengambilan sampel yang digunakan adalah cluster sampling sehingga terpilihlah 2 kelas. Penentuan kelas eksperimen dan kelas kontrol menggunakan undian sehingga diperoleh kelas VII A sebagai kelas eksperimen dan kelas VII B sebagai kelas kontrol. 
J. Pijar MIPA, Vol. 15 No.2, Maret 2020: 130-134

DOI: $10.29303 /$ jpm.v15i2.1544

Desain penelitian yang digunakan dalam penelitian ini adalah Nonequivalent Control Group Design. Di dalam penelitian ini terdapat 2 kelompok di mana masing-masing kelompok diberikan pretest. Selanjutnya pada kelompok eksperimen diterapkan model discovery learning. Sedangkan pada kelompok kontrol menerapkan metode konvensional. Pada akhir pembelajaran, masing-masing kelas diberikan posttest.

Penelitian ini menggunakan instrumen tes hasil belajar. Instrumen tes yang digunakan terdiri dari soal-soal pilihan ganda dan essay terbuka. Data yang diperoleh dari instrumen tes hasil belajar selanjutnya dilakukan pengujian normalitas data dan homogenitas data. Uji normalitas data diuji dengan menggunakan uji Kolmogorov Smirnov. Selanjutnya uji homogenitas data diuji dengan menggunakan uji Levene. Uji hipotesis penelitian diuji dengan menggunakan uji ANAKOVA (Analisis Kovarian) di mana data posttest dikoreksi data pretest. Efektivitas pembelajaran IPA dapat diketahui melalui NGainScore peserta didik. Pengujian normalitas, homogenitas, dan hipotesis dilakukan pada taraf signifikansi $5 \%$ dan dilakukan denganmenggunakan SPSS 21.

\section{HASIL DAN PEMBAHASAN}

Berdasarkan data hasil belajar peserta didik yang diperoleh, pada kelas eksperimen yang menerapkan model pembelajaran discovery learning mengalami peningkatan hasil belajar yang lebih baik dibandingkan dengan kelas kontrol yang menggunakan metode konvensional. Berdasarkan data yang diperoleh, rata-rata hasil pretest pada kelas kontrol adalah 59 dan pada kelas eksperimen adalah 57. Setelah dilakukannya kegiatan pembelajaran dengan menerapkan metode konvensioanl pada kelas kontrol dan model pembelajaran discovery learning pada kelas eksperimen, diperoleh rata-rata hasil posttest pada kelas kontrol adalah 74 dan pada kelas eksperimen adalah 79.

Peningkatan hasil belajar yang lebih baik pada kelas eksperimen daripada kelas kontrol disebabkan karena pada kelas eksperimen diterapkan model pembelajaran discovery learning. Pembelajaran dengan menggunakan model discovery learning berpusat pada peserta didik dan bukan pada guru. Peserta didik diberi kesempatan untuk mencari sendiri pengetahuannya sehingga pembelajaran lebih bermakna. Peserta didik menjadi lebih aktif selama kegiatan pembelajaran berlangsung. Model pembelajaran discovery learning dapat membantu peserta didik untuk menemukan materi yang dipelajari dan menghubungkannya dengan kondisi nyata sehingga dapat diterapkan dalam kehidupan seharihari [9]. Dalam pembelajaran model discovery learning, materi atau bahan pelajaran tidak disampaikan dalam bentuk final akan tetapi peserta didik didorong untuk mengidentifikasi apa yang ingin diketahui selanjutnya mencari informasi sendiri kemudian mengorganisasi atau membentuk apa yang diketahui dan pahami dalam bentuk akhir [10].

Hasil uji hipotesis yang diperoleh menunjukkan bahwa penerapan model pembelajaran discovery learning efektif terhadap hasil belajar IPA peserta didik di kelas VII SMP Negeri 14 Mataram semester genap tahun ajaran 2018/2019. Sejalan dengan penelitian-penelitian sebelumnya, dimana pembelajaran discovery learning lebih efektif dalam meningkatkan hasil belajar peserta didik dan terdapat peningkatan hasil belajar yang signifikan pada kelas eksperimen [11]. Hasil belajar peserta didik dengan menggunakan model pembelajaran discovery learning meningkat [12]. Hasil belajar peserta didik dengan menggunakan model discovery learning lebih efektif dibandingkan dengan pembelajaran yang menggunakan metode konvensional [13].

Berdasarkan data yang diperoleh seperti pada tabel 1, nilai signifikansi untuk kovariat adalah 0,000 dan lebih kecil dari 0,05 $(0,000<0,05)$. Hal ini dapat disimpulkan bahwa nilai pretest memiliki hubungan linear dengan nilai posttest. Selanjutnya, nilai signifikansi pada grup adalah 0,047 dan lebih kecil dari $0,05(0,047<0,05)$. Dapat disimpulkan bahwa model pembelajaran yang digunakan memiliki pengaruh terhadap hasil belajar IPA peserta didik. Nilai signifikansi yang diperoleh pada corrected model adalah 0,000 dan lebih kecil dari 0,05 (0,000 < 0,05). Dengan demikian dapat disimpulkan bahwa nilai pretest peserta didik dan model pembelajaran yang digunakan dapat mempengaruhi nilai posttest yang diperoleh oleh peserta didik. Keefektifan penerapan model pembelajaran discovery learning bisa dilihat dari NGain-Score peserta didik seperti pada tabel 2. Adapun nilai rata-rata NGain-Score pada kelas eksperimen yakni 0,4747. Sedangkan nilai ratarata NGain-Score yang diperoleh pada kelas kontrol yakni 0,3747. Nilai rata-rata NGain-Score yang diperoleh kelas eksperimen tidak jauh berbeda dengan kelas kontrol. Berdasarkan tabel klasifikasi nilai gain [14], kedua nilai rata-rata berada pada klasifikasi sedang. Namun, kelas eksperimen yang menggunakan model pembelajaran discovery learning memiliki nilai rata-rata NGain-Score yang lebih tinggi dibandingkan dengan kelas kontrol yang menggunakan metode konvensional. 
Tabel 1 Hasil Analisis Kovarian Hasil Belajar IPA Tests of Between-Subjects Effects

Dependent Variable: Posttest

\begin{tabular}{lccccc}
\hline \multicolumn{1}{c}{ Source } & $\begin{array}{c}\text { Type III Sum } \\
\text { of Squares }\end{array}$ & df & Mean Square & F & Sig. \\
\hline Corrected Model & $3132.980^{\mathrm{a}}$ & 2 & 1566.490 & 11.316 & .000 \\
Intercept & 5147.280 & 1 & 5147.280 & 37.182 & .000 \\
Pretest & 2746.730 & 1 & 2746.730 & 19.841 & .000 \\
Group & 570.070 & 1 & 570.070 & 4.118 & .047 \\
Error & 8582.959 & 62 & 138.435 & & \\
Total & 392801.000 & 65 & & & \\
Corrected Total & 11715.938 & 64 & & & \\
\hline
\end{tabular}

a. $\mathrm{R}$ Squared $=.267$ (Adjusted R Squared $=.244)$

Tabel 2 Hasil Ngain-Score Kelas Kontrol dan Kelas Eksperimen

\begin{tabular}{clccc}
\hline No & Kelas & Rata-Rata & Minimal & Maksimal \\
\hline 1 & Kontrol & 0,3747 & 0,02 & 0,91 \\
2 & Eksperimen & 0,4747 & 0,09 & 0,92 \\
\hline
\end{tabular}

Berdasarkan nilai rata-rata NGain-score masing-masing kelas yang tidak jauh berbeda menunjukkan bahwa dalam penerapan model pembelajaran discovery learning terdapat beberapa kekurangan karena disebabkan oleh beberapa faktor. Faktor-faktor tersebut diantaranya yaitu dibutuhkan waktu yang cukup untuk menerapkan model pembelajaran discovery learning, peserta didik membutuhkan waktu untuk menyesuaikan diri dalam menerapkan model pembelajaran discovery learning, sulit untuk mengontrol setiap peserta didik yang memiliki karakteristik yang berbeda-beda pada kelas yang memiliki jumlah peserta didik yang banyak. Jumlah peserta didik pada kelas eksperimen yaitu 33 orang dan pada kelas kontrol yaitu 32 orang. Jumlah peserta didik yang cukup banyak untuk setiap kelas menyebabkan tidak semua peserta didik dapat menerapkan model pembelajaran discovery learning secara optimal. Selain itu peserta didik juga harus beradaptasi dengan guru baru selama kegiatan pembelajaran dan soal-soal yang diberikan juga berpengaruh terhadap hasil belajar peserta didik. Berdasarkan kekurangan yang disebabkan oleh faktorfaktor tersebut, guru menerapkan model pembelajaran discovery learning secara bertahap. Kemudian guru membimbing peserta didik untuk menyelesaikan kesulitan-kesulitan yang dihadapi selama selama proses pembelajaran.

Kegiatan pembelajaran pada kelas kontrol yang menerapkan metode konvensional menghadapi kendala. Beberapa peserta didik berbicara dengan teman sebangkunya dan tidak memperhatikan penjelasan guru. Untuk mengembalikan fokus peserta didik, guru menegur dan memberikan pertanyaan singkat tentang materi yang telah dipelajari. Kurang optimalnya kegiatan pembelajaran pada kelas kontrol disebabkan karena peserta didik kurang terlibat dalam proses pembelajaran. Peserta didik cenderung hanya mendengarkan penjelasan materi pada bagian awal saja dan setelah itu kurang fokus pada penjelasan materi selanjutnya. Kegiatan pembelajaran lebih berpusat pada guru daripada peserta didik. Pembelajaran konvensional merupakan pembelajaran yang berfokus pada guru dan bukan peserta didik, pembelajaran bersifat pasif, interaksi selama kegiatan pembelajaran kurang terjadi, dan pengetahuan yang dimiliki peserta didik dikembangkan oleh guru [15]. Selanjutnya beberapa kelemahan dari metode ceramah, diantaranya yaitu mudah terjadinya verbalisme, lebih banyak auditif daripada visual, membosankan jika digunakan dalam waktu yang lama, sulit untuk mengetahui apakah peserta didik paham dan tertarik terhadap materi yang disampaikan, dan peserta didik menjadi pasif [16].

\section{KESIMPULAN}

Berdasarkan hasil penelitian yang telah dilakukan, maka dapat disimpulkan bahwa penerapan model discovery learning efektif terhadap hasil belajar IPA peserta didik di kelas VII SMP Negeri 14 Mataram semester genap tahun ajaran 2018/2019.

\section{DAFTAR PUSTAKA}

[1] Indonesia, P. R. (2003). Undang-undang Republik Indonesia nomor 20 tahun 2003 tentang sistem pendidikan nasional. Jakarta: Pemerintah Republik Indonesia.

[2] Ningsyih, S., Junaidi, E., \& Al Idrus, S. W. (2016). Pengaruh Pembelajaran Praktikum Berbasis Inkuiri Terbimbing Terhadap 
Kemampuan Berpikir Kritis Dan Hasil Belajar Kimia Siswa. Jurnal Pijar Mipa, 11(1).

[3] Fitri, M. (2015). Pengaruh model pembelajaran discovery learning terhadap hasil belajar siswa pada materi pokok suhu dan kalor. INPAFI (Inovasi Pembelajaran Fisika), 3(2).

[4] Rahmalia, Y. (2014). Efektivitas Model Discovery Learning Untuk Peningkatan Hasil Belajar Siswa Kelas X Pada Kompetensi Dasar Analisis Rangkaian Kemagnetan Di SMK 1 Pundong. Skripsi Tidak Dipublikasi. Universitas Negeri Yogyakarta, Yogyakarta.

[5] Lestari, W. (2017). Efektivitas model pembelajaran guided discovery learning terhadap hasil belajar matematika. SAP (Susunan Artikel Pendidikan), 2(1).

[6] Rosdiana, R., Boleng, D. T., \& Susilo, S. Pengaruh Penggunaan Model Discovery Learning terhadap Efektivitas dan Hasil Belajar Siswa. Jurnal Pendidikan: Teori, Penelitian, dan Pengembangan, 2(8).

[7] Mahdi, M., Savalas, L. R. T., \& Hakim, A. (2019). Pembelajaran Kimia Berorientasi Discovery untuk Meningkatkan Literasi Sains Peserta Didik. Jurnal Pijar Mipa, 14(2), 13-17.

[8] Kharisma, V. S. (2016). Efektivitas model discovery learning dengan pendekatan saintifik untuk meningkatkan hasil belajar siswa kelas $V$ pada pembelajaran IPA materi pokok Pesawat Sederhana di MI Tsamrotul Huda 01 Kecapi Jepara (Doctoral dissertation, UIN Walisongo).

[9] Izzatunnisa, I., Andayani, Y., \& Hakim, A. (2019). Pengembangan LKPD Berbasis Pembelajaran Penemuan Untuk Meningkatkan Kemampuan Literasi Sains Peserta Didik Pada Materi Kimia SMA. Jurnal Pijar Mipa, 14(2), 4954.

[10] Putri, R. H., Lesmono, A. D., \& Aristya, P. D. (2017). Pengaruh Model Discovery Learning Terhadap Motivasi Belajar dan Hasil Belajar Fisika Siswa MAN Bondowoso. Jurnal Pembelajaran Fisika, 6(2), 173-180.

[11] Hake, R. R. (1998). Interactive-engagement versus traditional methods: A six-thousandstudent survey of mechanics test data for introductory physics courses. American journal of Physics, 66(1), 64-74.

[12] Kumape, S. (2015). Pengaruh penerapan model pembelajaran kooperatif tipe two stay two stray terhadap aktivitas dan hasil belajar siswa tentang IPA di Kelas VI SD Inpres Palupi. Jurnal Kreatif Online, 4(4).

[13] Widayati, A. (2004). Metode mengajar sebagai strategi dalam mencapai tujuan belajar mengajar. Jurnal Pendidikan Akuntansi Indonesia, 3(1). 